\title{
Comparison between High-Sensitivity C-Reactive Protein (hs-CRP) and White Blood Cell Count (WBC) as an Inflammatory Component of Metabolic Syndrome in Japanese
}

\author{
Eiji Oda and Ryu Kawai
}

\begin{abstract}
Objective To compare two systemic inflammatory markers, high-sensitivity C-reactive protein (hs-CRP) and white blood cell count (WBC), as a component of metabolic syndrome (MetS).

Methods Data of hs-CRP and WBC from 2,185 Japanese men and 1,383 Japanese women were examined using receiver operating characteristic (ROC) curve for diagnosing MetS and Spearman's correlation coefficients.

Results The area under ROC curve (AUC) of hs-CRP was 0.71 in men and 0.74 in women. The AUC of WBC was 0.65 in men and 0.69 in women. The optimal cutoff point (sensitivity; specificity) of hs-CRP was $0.40 \mathrm{mg} / \mathrm{L}(0.69 ; 0.65)$ in men and $0.35 \mathrm{mg} / \mathrm{L}(0.67 ; 0.72)$ in women. The optimal cutoff point (sensitivity; specificity) of WBC was $5,600 / \mathrm{L}^{-6}(0.61 ; 0.61)$ in men and $5,000 / \mathrm{L}^{-6}(0.65 ; 0.63)$ in women. Correlations between obesity parameters, blood pressure, and liver function tests were stronger with hs-CRP than with WBC. But, no correlation between MetS-related risk factors was stronger with WBC than with hs-CRP.

Conclusion Hs-CRP is superior to WBC as an inflammatory component of MetS in Japanese. However, WBC may be useful when hs-CRP is not available because WBC is routinely measured in clinical practice.
\end{abstract}

Key words: metabolic syndrome, high-sensitivity CRP, white blood cell count, inflammation

(Inter Med 49: 117-124, 2010)

(DOI: 10.2169/internalmedicine.49.2670)

\section{Introduction}

Insulin resistance syndrome (syndrome X) (1) or metabolic syndrome (MetS) (2) is a constellation of interrelated metabolic risk factors that appear to directly promote the development of diabetes and cardiovascular disease. Recent studies indicate that MetS is associated with not only diabetes and cardiovascular disease but also fatty liver disease (3), chronic kidney disease (CKD) (4), atrial fibrillation (5), obstructive sleep apnea (6), and restrictive lung disease (7). The predominant underlying mechanisms of MetS appear to be insulin resistance (1), leptin resistance (8), abdominal obesity (9), autonomic dysfunction (8), endothelial dysfunction (10), and inflammation $(11,12)$. Inflammation may be a core mechanism of both MetS (11-13) and atherosclerotic cardiovascular disease (14). High-sensitivity C-reactive protein (hs-CRP), a marker of low-grade systemic inflammation, is reported as an independent risk factor of diabetes (15) and cardiovascular disease (16). In Western countries, hs-CRP levels lower than $1 \mathrm{mg} / \mathrm{L}$, between $1 \mathrm{mg} / \mathrm{L}$ and $3 \mathrm{mg} / \mathrm{L}$, and higher than $3 \mathrm{mg} / \mathrm{L}$ are considered as low risk, intermediate risk, and high risk categories, respectively (17). But, hs-CRP levels in Japanese are substantially lower than those in Westerners. Previously, we reported 0.45 $\mathrm{mg} / \mathrm{L}$ in men and $0.25 \mathrm{mg} / \mathrm{L}$ in women as a tentative cutoff point of hs-CRP as a component of MetS among Japanese (18). White blood cell count (WBC) is also a routinely measured marker of systemic inflammation and, recently, reported to be a risk factor of cardiovascular mortality in Japanese from NIPPON DATA 90 (19). 


\section{Methods}

\section{Subjects}

Between April 12008 and March 31 2009, 2,541 men and 1,502 women visited our medical check-up center for general health screening. Visitors were all required to fill out a questionnaire including questions about history of stroke and coronary heart disease, smoking and drinking status, and antihypertensive, hypoglycemic, and antihyperlipidemic medications. Among these persons 25 men and 20 women without signed consent, 18 men and 17 women lacking some laboratory data, and 33 men and 12 women with hsCRP levels of higher than $10 \mathrm{mg} / \mathrm{L}$ were excluded from the subjects resulting in 2,449 men and 1,448 women. Then, 104 men and 23 women with a history of coronary heart disease, 35 men and 16 women with a history of stroke, and 125 men and 26 women with diabetes were further excluded resulting in 2,185 men and 1,383 women. The protocol for the present study was approved by the ethics committee at Tachikawa Medical Center and signed informed consent was obtained from each subject.

\section{Measurements}

After an overnight fast, blood samples were obtained to measure blood levels of routine medical check-up tests: glucose, triglycerides, high-density lipoprotein (HDL) cholesterol, low-density lipoprotein (LDL) cholesterol, hemoglobin A1c, uric acid, blood cell counts, electrolytes, liver and kidney function tests, and hs-CRP. Simple qualitative urinalyses were performed with test papers. Chemical measurements were all performed at BML Nagaoka (Nagaoka, Japan) with routine laboratory methods except for hs-CRP which was measured at BML General Laboratory (Tokyo, Japan) with nephelometry using N-latex CRP-2 (Siemens Healthcare Japan, Tokyo, Japan). The measurement limit of hs-CRP was $0.02 \mathrm{mg} / \mathrm{L}$ and the value of hs-CRP less than the measurement limit was considered as $0.01 \mathrm{mg} / \mathrm{L}$. LDL cholesterol was measured with a direct surfactant method using Choletest-LDL (Sekisui Medical Inc, Tokyo, Japan). Estimated glomerular filtration rate (eGFR) was calculated as eGFR $\left(\mathrm{mL} / \mathrm{min} / 1.73 \mathrm{~m}^{2}\right)=194 \times$ creatinine $^{-1.094} \times$ age $^{-0.287}$ in men, and $194 \times$ creatinine $e^{-1.094} \times$ age $e^{-0.287} \times 0.739$ in women according to the recommendation from the Japanese Society of Nephrology. Body fat percentage was measured with bioelectrical impedance analysis using TBF-210 (TANITA, Tokyo, Japan). An average systolic blood pressure (SBP) and diastolic blood pressure (DBP) was calculated from two measurements with the subjects in a sitting position after a 5 minutes rest period. Heart rate was automatically recorded with electrocardiography. Body weight was measured with the subjects wearing lightweight clothes provided by our center and the weight of the clothing was subtracted from the measured body weight. Waist circumference was measured at the level of the umbilicus. Body mass index (BMI) was calculated as weight in kilograms divided by the square of height in meters.

\section{Definitions}

We adopted the revised National Cholesterol Education Program (NCEP) definition (20) for MetS because the Japanese definition of MetS (21) which includes obesity as an inevitable component was already revealed to be inappropriate by recent large longitudinal epidemiological studies (22-25). The revised NCEP criteria of MetS (20) was defined as three or more of five components where the cutoff point of waist circumference was modified for Japanese as $\geq 90 \mathrm{~cm}$ in men and $\geq 80 \mathrm{~cm}$ in women according to the recommendation by International Diabetes Federation (IDF) (9). The cutoff points of other components were SBP $\geq 130 \mathrm{mmHg}$ and/or DBP $\geq 85 \mathrm{mmHg}$ for blood pressure, $\geq 150 \mathrm{mg} / \mathrm{dL}$ for triglycerides, $<40 \mathrm{mg} / \mathrm{dL}$ in men and $<50$ $\mathrm{mg} / \mathrm{dL}$ in women for HDL cholesterol, and $\geq 100 \mathrm{mg} / \mathrm{dL}$ for fasting glucose. Subjects receiving antihypertensive or hypoglycemic medication were considered to have the respective component. Diabetes was defined as fasting glucose $\geq 126 \mathrm{mg} / \mathrm{dL}$ and/or hypoglycemic medication. Chronic kidney disease (CKD) was defined as eGFR $<60 \mathrm{~mL} / \mathrm{min} / 1.73$ $\mathrm{m}^{2}$ and/or proteinuria.

\section{Statistical analysis}

Medians of hs-CRP and means of WBC in each category defined by the number of MetS components were calculated. Receiver operating characteristic (ROC) curve analysis for diagnosing MetS was performed to obtain area under ROC curve (AUC) and optimal cutoff points of hs-CRP and WBC for diagnosing MetS. Hs-CRP was transformed to logarithm because it was skewed. An optimal cutoff point was defined as a point on a ROC curve nearest to the point where both sensitivity and specificity were one. Spearman's correlation coefficients were calculated between hs-CRP and MetSrelated risk factors and between WBC and MetS-related risk factors, and these calculations were repeated excluding current smokers. Statistical analyses were performed using Dr SPSS-2 (SPSS Japan Inc., Tokyo, Japan). Means were compared with two-sided t-tests, ratios were compared with chisquare tests, and correlation coefficients were compared with Fisher's z-transformations. P values of lower than 0.05 were considered to be statistically significant.

\section{Results}

Basal data are shown in Table 1. The frequency of MetS was $12.4 \%$ in men and $7.6 \%$ in women and the frequency of CKD was $7.7 \%$ in men and $7.5 \%$ in women. Medians of hs-CRP and means of WBC in each category defined by the number of MetS components are presented in Table 2. The median of hs-CRP in $0,1,2,3$, and 4 or 5 MetS component category was $0.22 \mathrm{mg} / \mathrm{L}, 0.29 \mathrm{mg} / \mathrm{L}, 0.41 \mathrm{mg} / \mathrm{L}, 0.53 \mathrm{mg} / \mathrm{L}$, and $0.62 \mathrm{mg} / \mathrm{L}$, respectively in men and $0.15 \mathrm{mg} / \mathrm{L}, 0.27$ $\mathrm{mg} / \mathrm{L}, 0.30 \mathrm{mg} / \mathrm{L}, 0.50 \mathrm{mg} / \mathrm{L}$, and $0.75 \mathrm{mg} / \mathrm{L}$, respectively in 
Table 1. Basal Data

\begin{tabular}{cccc}
\hline & men & women & \\
$\mathrm{n}$ & $\mathrm{n}=2185$ & $\mathrm{n}=1383$ & $\mathrm{p}$ \\
\hline age $(\mathrm{years})$ & $51.2 \pm 9.4$ & $51.2 \pm 9.7$ & $\mathrm{~ns}$ \\
BMI $\left(\mathrm{kg} / \mathrm{m}^{2}\right)$ & $23.0 \pm 2.9$ & $21.7 \pm 3.0$ & $<0.0001$ \\
body fat percentage (\%) & $22.1 \pm 5.0$ & $26.6 \pm 5.9$ & $<0.0001$ \\
waist circumference $(\mathrm{cm})$ & $83.8 \pm 8.0$ & $78.9 \pm 8.5$ & $<0.0001$ \\
SBP $(\mathrm{mmHg})$ & $121.5 \pm 17.3$ & $112.1 \pm 17.0$ & $<0.0001$ \\
DBP $(\mathrm{mmHg})$ & $77.2 \pm 10.7$ & $70.1 \pm 10.3$ & $<0.0001$ \\
fasting glucose $(\mathrm{mg} / \mathrm{dL})$ & $93.4 \pm 8.8$ & $88.8 \pm 8.3$ & $<0.0001$ \\
triglycerides $(\mathrm{mg} / \mathrm{dL})$ & $120.6 \pm 74.3(101)$ & $83.1 \pm 47.3(71)$ & $<0.0001$ \\
HDL cholesterol $(\mathrm{mg} / \mathrm{dL})$ & $58.0 \pm 14.5$ & $67.3 \pm 14.6$ & $<0.0001$ \\
hs-CRP $(\mathrm{mg} / \mathrm{L})$ & $0.60 \pm 0.95(0.30)$ & $0.46 \pm 0.78(0.22)$ & $<0.0001$ \\
GGT $(\mathrm{U} / \mathrm{L})$ & $51.3 \pm 53.8(35)$ & $23.5 \pm 20.4(17)$ & $<0.0001$ \\
ALT $(\mathrm{U} / \mathrm{L})$ & $26.6 \pm 18.8(22)$ & $18.0 \pm 13.6(15)$ & $<0.0001$ \\
WBC $\left(/ \mathrm{L}^{-6}\right)$ & $5536 \pm 1470$ & $4864 \pm 1281$ & $<0.0001$ \\
uric acid $(\mathrm{mg} / \mathrm{dL})$ & $6.1 \pm 1.3$ & $4.4 \pm 1.0$ & $<0.0001$ \\
LDL cholesterol $(\mathrm{mg} / \mathrm{dL})$ & $121.5 \pm 29.7$ & $120.7 \pm 29.6$ & $\mathrm{~ns}$ \\
hemoglobin A1c $(\%)$ & $5.0 \pm 0.3$ & $5.0 \pm 0.3$ & $\mathrm{~ns}$ \\
MetS & 12.4 & 6.9 & $<0.0001$ \\
chronic kidney disease & 7.7 & 7.5 & $\mathrm{~ns}$ \\
antihypertensives & 14.8 & 8.7 & $<0.0001$ \\
antihyperlipidemics & 6.7 & 9.3 & $<0.01$ \\
current smokers & 34.4 & 7.8 & $<0.0001$ \\
everyday drinkers & 51.3 & 15.5 & $<0.0001$ \\
\hline
\end{tabular}

Values are presented as mean \pm SD or \%. BMI: body mass index, SBP: systolic blood pressure, DBP: diastolic blood pressure, HDL: high-density lipoprotein, hs-CRP: high-sensitivity C-reactive protein, GGT: gamma glutamyltransferase, ALT: alanine aminotransferase, WBC: white blood cell count, LDL: low-density lipoprotein, MetS: metabolic syndrome.

Table 2. Hs-CRP and WBC by the Number of MetS Components

\begin{tabular}{|c|c|c|c|c|c|c|}
\hline \multirow[b]{2}{*}{ MetS components } & \multicolumn{3}{|c|}{ men } & \multicolumn{3}{|c|}{ women } \\
\hline & $\mathrm{n}$ & hs-CRP (mg/L) & WBC $\left(/ L^{-6}\right)$ & $\mathrm{n}$ & hs-CRP (mg/L) & WBC $\left(/ L^{-6}\right)$ \\
\hline 0 & 833 & $0.22(0.12,0.41)$ & $5232 \pm 1367$ & 612 & $0.15(0.07,0.27)$ & $4670 \pm 1272$ \\
\hline 1 & 673 & $0.29(0.16,0.54)$ & $5454 \pm 1468$ & 464 & $0.27(0.15,0.51)$ & $4864 \pm 1209$ \\
\hline 2 & 409 & $0.41(0.24,0.75)$ & $5864 \pm 1478$ & 202 & $0.30(0.16,0.62)$ & $5077 \pm 1358$ \\
\hline 3 & 195 & $0.53(0.30,1.18)$ & $6063 \pm 1431$ & 83 & $0.50(0.25,0.83)$ & $5416 \pm 1163$ \\
\hline 4 or 5 & 75 & $0.62(0.44,1.27)$ & $6497 \pm 1561$ & 22 & $0.75(0.54,1.60)$ & $6205 \pm 1066$ \\
\hline
\end{tabular}

women. The means of WBC in $0,1,2,3$, and 4 or 5 MetS component category was $5,232 / \mathrm{L}^{-6}, 5,454 / \mathrm{L}^{-6}, 5,864 / \mathrm{L}^{-6}$, $6,063 / \mathrm{L}^{-6}$, and $6,497 / \mathrm{L}^{-6}$, respectively in men and $4,670 / \mathrm{L}^{-6}$, $4,864 / \mathrm{L}^{-6}, 5,077 / \mathrm{L}^{-6}, 5,416 / \mathrm{L}^{-6}$, and $6,205 / \mathrm{L}^{-6}$, respectively in women. ROC curves of hs-CRP and WBC for diagnosing MetS are shown in Fig. 1. AUC of hs-CRP and WBC for diagnosing MetS and optimal cutoff points of hs-CRP and WBC as a component of MetS are presented in Table 3. The AUC and its 95\% confidence interval (CI) of hs-CRP were 0.71 and $0.68-0.75$ in men and 0.74 and $0.70-0.79$ in women. The AUC and its $95 \%$ CI of WBC were 0.65 and 0.62-0.69 in men and 0.69 and 0.64-0.74 in women. The optimal cutoff point (sensitivity; specificity) of hs-CRP was $0.40 \mathrm{mg} / \mathrm{L}(0.69 ; 0.65)$ in men and $0.35 \mathrm{mg} / \mathrm{L}(0.67 ; 0.72)$ in women. The optimal cutoff point (sensitivity; specificity) of WBC was $5,600 / \mathrm{L}^{-6}(0.61 ; 0.61)$ in men and $5,000 / \mathrm{L}^{-6}$ $(0.65 ; 0.63)$ in women. Spearman's correlation coefficients between hs-CRP or WBC and MetS-related risk factors are shown in Table 4. The Spearman's correlation coefficients between BMI, body fat \%, waist circumference, SBP, DBP, GGT, and uric acid were significantly stronger with hs-CRP than with WBC in men and those between BMI, body fat $\%$, waist circumference, DBP, GGT, ALT, LDL cholesterol, uric acid, and hemoglobin Alc were significantly stronger with hs-CRP than with WBC in women. There was no significantly stronger correlation between WBC and other MSrelated risk factors than those between hs-CRP and other MS-related risk factors. Table 5 shows similar correlation coefficients in subjects excluding current smokers. The correlation coefficients were essentially the same except for the 

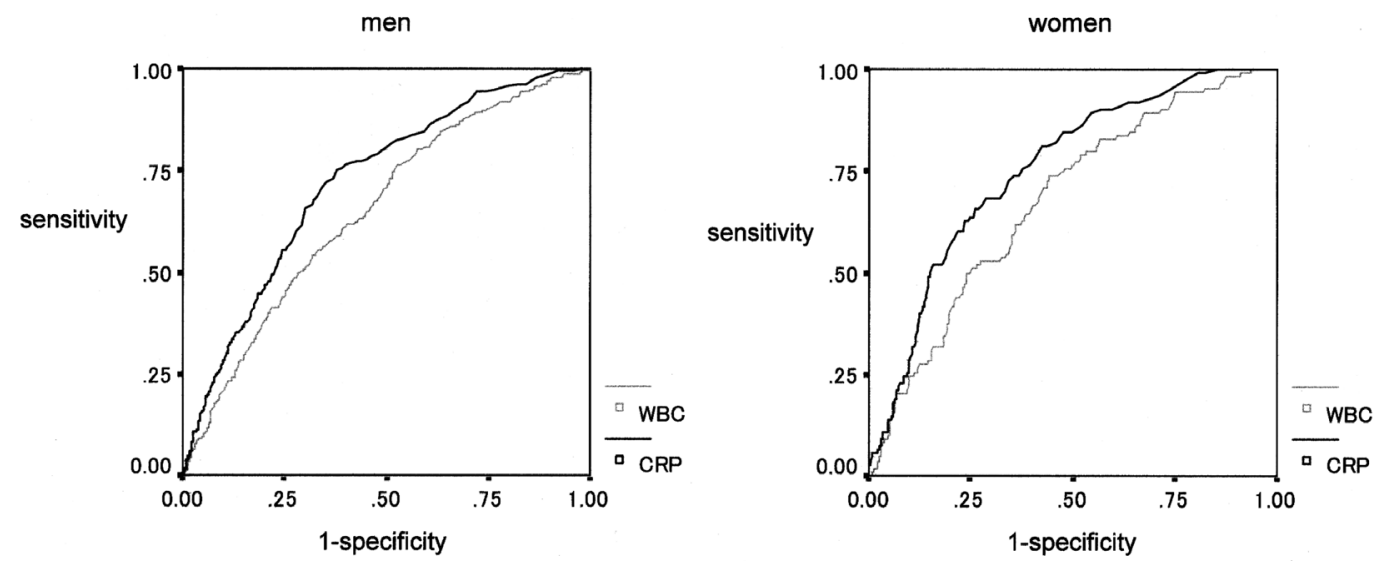

Figure 1. Receiver operating characteristic curves of high-sensitivity C-reactive protein (CRP) and white blood cell count (WBC) for diagnosing metabolic syndrome.

Table 3. AUC and Optimal Cut Points of Hs-CRP and WBC for Diagnosing Metabolic Syndrome

\begin{tabular}{cccccccc}
\hline \multirow{2}{*}{ men } & AUC & \multicolumn{2}{c}{$95 \%$ Cl of AUC } & optimal cutoff point & sensitivity & specificity \\
& hs-CRP & 0.71 & 0.68 & 0.75 & $0.40 \mathrm{mg} / \mathrm{L}$ & 0.69 & 0.65 \\
\multirow{3}{*}{ women } & WBC & 0.65 & 0.62 & 0.69 & $5600 / L^{-6}$ & 0.61 & 0.61 \\
& hs-CRP & 0.74 & 0.70 & 0.79 & $0.35 \mathrm{mg} / \mathrm{L}$ & 0.67 & 0.72 \\
\hline
\end{tabular}

AUC: area under receiver operating characteristic curve, $\mathrm{Cl}$ : confidence interval. Other abbreviations are the same as Table 1.

Table 4. Spearman's Correlation Coefficients of Hs-CRP and WBC with Other Metabolic Risk Factors

\begin{tabular}{|c|c|c|c|c|}
\hline \multirow{3}{*}{$\mathrm{n}$} & \multicolumn{2}{|c|}{ men } & \multicolumn{2}{|c|}{ women } \\
\hline & \multicolumn{2}{|c|}{2185} & \multicolumn{2}{|c|}{1383} \\
\hline & hs-CRP & WBC & hs-CRP & WBC \\
\hline $\mathrm{BMI}$ & 0.376 & $0.223^{\#}$ & 0.357 & $0.184^{\#}$ \\
\hline body fat $\%$ & 0.343 & $0.191^{* *}$ & 0.358 & $0.199^{*}$ \\
\hline waist circumference & 0.344 & $0.223^{\#}$ & 0.331 & $0.138^{\#, \dagger}$ \\
\hline systolic blood pressure & 0.201 & $0.091^{\star \star \star}$ & 0.216 & $0.162^{\dagger}$ \\
\hline diastolic blood pressure & 0.174 & $0.081^{\star \star}$ & 0.206 & $0.118^{*}$ \\
\hline fasting glucose & 0.118 & 0.071 & 0.163 & 0.091 \\
\hline triglycerides & 0.293 & 0.302 & 0.281 & $0.211^{\dagger \dagger}$ \\
\hline HDL cholesterol & -0.308 & -0.284 & -0.255 & $-0.192^{\dagger \dagger}$ \\
\hline GGT & 0.252 & $0.170^{\star \star}$ & $0.314^{\dagger}$ & $0.121^{\#}$ \\
\hline ALT & 0.214 & 0.158 & 0.213 & $0.033^{\#, \mathrm{t \dagger}}$ \\
\hline LDL cholesterol & 0.143 & 0.139 & 0.186 & $0.032^{\#, t \dagger}$ \\
\hline uric acid & 0.215 & $0.126^{\star \star}$ & 0.274 & $0.159^{* *}$ \\
\hline hemoglobin A1C & 0.175 & 0.125 & 0.200 & $0.063^{* \star \star}$ \\
\hline
\end{tabular}

slightly stronger correlations between WBC and obesity indices or blood pressures in men compared with Table 4.

\section{Discussion}

In the past several decades, there has been considerable effort to understand the underlying biology and to identify the risk factors of cardiovascular diseases. As risk factors were identified, it became apparent that they tended to cluster in the same individual. Thus, the concept of insulin resistance syndrome (syndrome X) (1) or MetS (2) emerged.
However, in 2005, the American Diabetes Association and the European Association for the Study of Diabetes jointly stated that no existing definition of MetS meets criteria as a syndrome (26) and there have been endless debates on the pros and cons of diagnosing this syndrome for individuals (27-30). Criteria that regard obesity as an inevitable component of MetS have a serious pit hole because there are a substantial number of metabolically obese normal weight individuals (31) and only about one third of the most insulin resistant individuals are actually obese (29). An essential drawback of Japanese MetS (visceral fat syn- 
Table 5. Spearman's Correlation Coefficients of Hs-CRP and WBC with Other Metabolic Risk Factors Excluding Current Smokers

\begin{tabular}{|c|c|c|c|c|}
\hline \multirow{3}{*}{$\mathrm{n}$} & \multicolumn{2}{|c|}{ men } & \multicolumn{2}{|c|}{ women } \\
\hline & \multicolumn{2}{|c|}{1434} & \multicolumn{2}{|c|}{1275} \\
\hline & CRP & WBC & CRP & WBC \\
\hline BMI & 0.372 & $0.265^{\star *}$ & 0.352 & $0.168^{\#,+\dagger}$ \\
\hline body fat $\%$ & 0.389 & $0.269^{\star \star *}$ & 0.400 & $0.195^{\#, \dagger}$ \\
\hline waist circumference & 0.372 & $0.255^{\star \star *}$ & 0.378 & $0.167^{\#, \dagger}$ \\
\hline systolic blood pressure & 0.208 & 0.151 & 0.223 & 0.152 \\
\hline diastolic blood pressure & 0.188 & 0.141 & 0.207 & $0.105^{\star *}$ \\
\hline fasting glucose & 0.104 & 0.091 & 0.159 & $0.067^{*}$ \\
\hline triglycerides & 0.264 & 0.307 & 0.276 & $0.199^{*}, t \dagger$ \\
\hline HDL cholesterol & -0.277 & -0.257 & -0.260 & $-0.173^{*}, \dagger$ \\
\hline GGT & 0.260 & $0.170^{*}$ & 0.307 & $0.094^{\#, \dagger}$ \\
\hline ALT & 0.239 & 0.191 & 0.202 & $0.020^{\#, \mp}$ \\
\hline LDL cholesterol & 0.151 & 0.146 & 0.185 & $0.031^{\#,+\dagger}$ \\
\hline uric acid & 0.214 & 0.153 & 0.259 & $0.147^{* *}$ \\
\hline hemoglobin A1c & 0.160 & 0.132 & 0.203 & $0.064^{\star \star \star}$ \\
\hline
\end{tabular}

drome) (21) is that it regards subcutaneous adipose tissue as a protective factor against the morbid effect of visceral adipose tissue (VAT) and ignores the risk contribution of abdominal subcutaneous adipose tissue (SAT). In 2007, comparing correlations of VAT volume and SAT volume with metabolic risk factors, inflammatory markers, markers of oxidative stress, and markers of endothelial dysfunction in Framingham Heart Study, it was clearly shown that the risk contribution of SAT cannot be ignored $(32,33)$. Furthermore, standardized odds ratios of VAT area, SAT area, BMI, and waist circumference for coronary calcification detected by electron beam CT, which is considered as an early manifestation of coronary artery disease, are 1.9, 2.0, 2.2, and 1.9 , respectively in men and $1.8,1.9,1.9$, and 2.0 , respectively in women (34). Thus, VAT area is not superior to SAT area, BMI, or waist circumference as a risk factor of coronary artery disease though the superiority of VAT area as a risk factor of coronary artery disease is the original reason of the proposition of visceral fat syndrome (35). As for insulin resistance, Reaven reviewed world literature comparing VAT area and SAT area regarding insulin resistance and concluded that the correlations of VAT area and SAT area with insulin sensitivity are not statistically different (29). Koutsari and Jensen showed that free fatty acid (FFA) released by VAT contributes only a small percentage of systemic FFA delivery and upper-body SAT is the dominant contributor to circulating FFAs, and that SAT could be more important than VAT as a cause of peripheral insulin resistance (36). A detailed criticism against visceral fat syndrome was discussed in a review (12). Japanese MetS or IDF MetS where obesity is an inevitable component of MetS was already revealed to be inferior to revised NCEP MetS as a predictor of cardiovascular disease in Japanese $(24,25)$. Therefore, in the present study, revised NCEP criteria where obesity is not an inevitable component was adopted as the definition of MetS.

Inflammation is a link between obesity and insulin resistance (13) and is thought to be a fundamental mechanism of MetS $(11,12)$. Hs-CRP is an independent risk factor of diabetes (15) and cardiovascular disease (16) and it is proposed as a component of MetS (16). Previously, we studied the cutoff point of hs-CRP as a component of MetS with a small-sized data (179 men and 166 women) and with a relatively rough hs-CRP measurement method (the measurement limit was $0.1 \mathrm{mg} / \mathrm{L}$ ) and reported $0.65 \mathrm{mg} / \mathrm{L}$ as an optimal cutoff point of hs-CRP in Japanese for both men and women (37). Later, we restudied with data from 1,062 men and 647 women and with a more sensitive hs-CRP measurement method (the measurement limit was $0.02 \mathrm{mg} / \mathrm{L}$ ) and reported $0.45 \mathrm{mg} / \mathrm{L}$ in men and $0.25 \mathrm{mg} / \mathrm{L}$ in women as a cutoff point of hs-CRP for a component of MetS in Japanese (18). Nagasawa et al studied the association between WBC and MetS in Japanese men, not in women, using BMI instead of waist circumference (38) and Ishizaka et al also studied the association between WBC and Japanese MetS defined by the Examination Committee for Criteria of Metabolic Syndrome (21) in Japanese men, not in women (39). Tamakoshi et al reported that elevated WBC was nearly significantly associated with a high risk of cardiovascular disease mortality in Japanese (19).

In the present study, we compared hs-CRP and WBC as an inflammatory component of MetS. The AUC of hs-CRP was 0.71 in men and 0.74 in women. The AUC of WBC was 0.65 in men and 0.69 in women. The optimal cutoff point (sensitivity; specificity) of hs-CRP was $0.40 \mathrm{mg} / \mathrm{L}$ $(0.69 ; 0.65)$ in men and $0.35 \mathrm{mg} / \mathrm{L}(0.67 ; 0.72)$ in women. The optimal cutoff point (sensitivity; specificity) of WBC was $5,600 / \mathrm{L}^{-6}(0.61 ; 0.61)$ in men and $5,000 / \mathrm{L}^{-6}(0.65$; 
0.63) in women. Correlations between obesity parameters, blood pressure, and liver function tests were stronger with hs-CRP than with WBC. But, no correlation between MetSrelated risk factors was stronger with WBC than with hsCRP. Therefore, hs-CRP was thought to be superior to WBC as an inflammatory component of MetS in Japanese.

In the present study, the optimal cutoff point of hs-CRP was $0.40 \mathrm{mg} / \mathrm{L}(0.69 ; 0.65)$ in men and $0.35 \mathrm{mg} / \mathrm{L}(0.67$; 0.72 ) in women. We excluded subjects with diabetes or with a history of stroke or coronary heart disease in the present study. In contrast, these subjects were included in previous studies $(18,37)$. Thus, $0.40 \mathrm{mg} / \mathrm{L}$ in men and $0.35 \mathrm{mg} / \mathrm{L}$ in women may be better than $0.45 \mathrm{mg} / \mathrm{L}$ in men and $0.25 \mathrm{mg} /$ $\mathrm{L}$ in women (18) as a cutoff point of hs-CRP for a MetS component in Japanese. The median hs-CRP in subjects with no MetS component was $0.22 \mathrm{mg} / \mathrm{L}$ in men and 0.15 $\mathrm{mg} / \mathrm{L}$ in women but the median hs-CRP in subjects with 4 or $5 \mathrm{MetS}$ components was $0.62 \mathrm{mg} / \mathrm{L}$ in men and $0.75 \mathrm{mg} /$ $\mathrm{L}$ in women. Saltevo et al reported that blood levels of hsCRP are significantly higher in women with MetS than in men with MetS, but in subjects without MetS, there are no gender differences in the level of hs-CRP (40). Lakoski et al reported that women have substantially higher median hsCRP levels compared with men (41). However, in Japanese, hs-CRP levels in women without MetS are lower than the levels in men, but in subjects with MetS, the gender difference in the level of CRP may be obscured. Thus, clustering of MetS components exerts a stronger influence on hs-CRP in women than in men as already reported by Nakanishi et al (42). The reason for this gender difference is unknown, but the association of LDL cholesterol with MetS is also stronger in Japanese women than in men (43). These stronger associations between MetS and other cardiovascular risk factors may cause a greater risk of cardiovascular mortality associated with MetS in women than in men (44). These cutoff points of hs-CRP are very low compared with the standard in Western societies where obesity prevails (17). However, we reported that very low levels of hsCRP are significantly related with other metabolic risk factors in Japanese (45). Doi et al reported that men with hsCRP of $0.29-0.77 \mathrm{mg} / \mathrm{L}$ have an age-adjusted odds ratio (95\% confidence interval) for incident diabetes of 2.67 (1.28-5.56) compared with men with hs-CRP of 0.05-0.28 $\mathrm{mg} / \mathrm{L}$ and that women with hs-CRP of $0.25-0.57 \mathrm{mg} / \mathrm{L}$ have an age-adjusted odds ratio (95\% confidence interval) for incident diabetes of $2.12(0.98-4.58)$ compared with women with hs-CRP of $0.05-0.24 \mathrm{mg} / \mathrm{L}$ in Japanese (15). Women with hs-CRP values $\geq 0.5 \mathrm{mg} / \mathrm{L}$ had a higher risk for cardiovascular disease than women with hs-CRP values $<0.5$ $\mathrm{mg} / \mathrm{L}$ even in the United States (46) where hs-CRP values are very high compared with those in Japan.

Tamakoshi et al studied WBC as a predictor of cardiovascular mortality with data from NIPPON DATA 90 and reported that subjects with WBC of $9,000-10,000 / \mathrm{L}^{-6}$ had a relative risk of 1.79 (95\% confidence interval; 0.97-3.71) compared with subjects with WBC of $4,000-4,900 / \mathrm{L}^{-6}(19)$.
They excluded subjects with WBC lower than $4,000 / \mathrm{L}^{-6}$ regarding them as in a pathological state of leucopenia both in men and in women. In the present study, $11 \%$ of men and $26 \%$ of women had WBC of lower than $4,000 / \mathrm{L}^{-6}$. Therefore, it might be possible that the cardiovascular mortality risk of WBC became higher if subjects with WBC lower than $4,000 / \mathrm{L}^{-6}$ were included in the reference groups. Margolis et al reported that, compared with women in the first quartile of WBC $\left(2,500-4,700 / \mathrm{L}^{-6}\right)$, women in the fourth quartile $\left(6,700-5,000 / \mathrm{L}^{-6}\right)$ had over a 2 -fold elevated risk for CHD death (hazard ratio, 2.36; 95\% confidence interval, 1.51-3.68) after multivariable adjustment for age, race, diabetes, hypertension, smoking, hypercholesterolemia, BMI, alcohol intake, diet, physical activity, aspirin use, and hormone use; women in the upper quartile of the WBC also had a $40 \%$ higher risk for nonfatal myocardial infarction, a $46 \%$ higher risk for stroke, and a 50\% higher risk for total mortality (47). Further, in multivariable models adjusting for hs-CRP, the WBC was an independent predictor of cardiovascular disease and they concluded that WBC, a stable, well-standardized, widely available and inexpensive measure of systemic inflammation, is an independent predictor of cardiovascular disease events and all-cause mortality in postmenopausal women (47). Thus, WBC may be a useful marker of cardiovascular disease risk.

As for the gender differences in the correlations between hs-CRP or WBC and other metabolic risk factors, the higher frequency of current smokers in men might have some effects on the differences because cigarette smoking increases WBC (48) and triglycerides (49) but decreases HDL cholesterol (49) and blood pressure (50). However, the correlation coefficients after the exclusion of current smokers were essentially the same as before the exclusion except for the slightly stronger correlations between WBC and obesity indices or blood pressures in men after exclusion. Thus, there may be other unknown causes for the gender differences in the correlations between hs-CRP or WBC and other metabolic risk factors.

\section{Conclusions and limitations}

Hs-CRP may be superior to $\mathrm{WBC}$ as an inflammatory component of MetS in Japanese. However, WBC may be useful as an alternative inflammatory component of MetS when hs-CRP is not available because WBC is routinely measured as a systemic marker of inflammation in clinical practice. The present study was a cross-sectional study and the subjects were not a general population but visitors to a medical check-up center which is in a central city of a rural region in Japan. Longitudinal studies are required to establish hs-CRP and WBC as risk factors of cardiovascular disease in Japanese.

\section{Acknowledgement}

We thank all subjects who participated in the study, the paramedical staff at our center who assisted with the study, and Dr. Shinzo Tachikawa, Dr. Shinpei Yoshii, and Dr. Masaaki Okabe at 
Tachikawa Medical Center, and Professor Yoshifusa Aizawa at Niigata University Graduate School of Medical and Dental Sci- ences for their effort to construct the study environment. We received no grant and have no conflict of interest to declare.

\section{References}

1. Reaven GM. Role of insulin resistance in human disease. Diabetes 37: 1595-1607, 1988.

2. World Health Organization. Definition, diagnosis, and classification of diabetes mellitus and its complications: report of a WHO Consultation. World Health Org, Geneva, 1999.

3. Kotronen A, Yki-Jarvinen H. Fatty liver: A novel component of the metabolic syndrome. Arterioscler Thromb Vasc Biol 28: 27-38, 2008.

4. Chen J, Muntner P, Hamm LL, et al. The metabolic syndrome and chronic kidney disease in U.S. adults. Ann Intern Med 140: 167174, 2004.

5. Watanabe $\mathrm{H}$, Tanabe $\mathrm{N}$, Watanabe $\mathrm{T}$, et al. Metabolic syndrome and risk of development of atrial fibrillation: The Niigata Preventive Medicine Study. Circulation 117: 1255-1260, 2008.

6. Pillar G, Shehadeh N. Abdominal fat and sleep apnea: The chicken or the egg? Diabetes Care 31: S303-S309, 2008.

7. Yeh H, Punjabi NM, Wang N, Pankow JS, Duncan BB, Brancati FL. Vital capacity as a predictor of incident type 2 diabetes. The atherosclerosis risk in communities study. Diabetes Care 28: 14721479,2005

8. Katagiri H, Yamada T, Oka Y. Adiposity and cardiovascular disorders: disturbance of the regulatory system consisting of humoral and neuronal signals. Circ Res 101: 27-39, 2007.

9. Alberti KG, Zimmet P, Shaw J. Metabolic syndrome-a new world-wide definition. A consensus statement from the International diabetes federation. Diabet Med 23: 469-480, 2006.

10. Kim J, Montagnani M, Koh KK, Quon MJ. Reciprocal relationships between insulin resistance and endothelial dysfunction. Molecular and pathophysiological mechanisms. Circulation 113: 1888-1904, 2006.

11. Dandona P, Aljada A, Chaudhuri A, Mohanty P, Garg R. Metabolic syndrome: a comprehensive perspective based on interactions between obesity, diabetes, and inflammation. Circulation 111: 1448-1454, 2005.

12. Oda E. The metabolic syndrome as a concept of adipose tissue disease. Hypertens Res 31: 1283-1291, 2008.

13. Hotamisligil GS, Shargill NS, Spiegelman BM. Adipose expression of tumor necrosis factor- $\alpha$ : direct role in obesity-linked insulin resistance. Science 259: 87-91, 1993.

14. Hansson GK. Inflammation, atherosclerosis, and coronary artery disease. N Engl J Med 352: 1685-1695, 2005.

15. Doi Y, Wakugawa Y, Kiyohara Y, et al. Elevated C-reactive protein is a predictor of diabetes in a general Japanese population: the Hisayama study. Diabetes Care 28: 2497-2500, 2005.

16. Ridker PM, Wilson PWF, Grandy SM. Should C-reactive protein be added to metabolic syndrome and to assessment of global cardiovascular risk? Circulation 109: 2818-2825, 2004.

17. Pearson TA, Mensah GA, Alexander RW, et al. Application to clinical and public health practice: a statement for healthcare professionals from the Centers for Disease Control and Prevention and the American Heart Association. Circulation 107: 499-511, 2003.

18. Oda E, Kawai R. Tentative cut point of high-sensitivity C-reactive protein for a component of metabolic syndrome in Japanese. Circ J 73: 755-759, 2009.

19. Tamakoshi $\mathrm{K}$, Toyoshima $\mathrm{H}$, Yatsuya $\mathrm{H}$, et al. White blood cell count and risk of all-cause and cardiovascular mortality in nationwide sample of Japanese. Results from NIPPON DATA 90. Circ J 71: 479-485, 2007.

20. Grundy SM, Cleeman JI, Daniels SR, et al. Diagnosis and man- agement of the metabolic syndrome: a statement for health care professionals: an American Heart Association/National Heart, Lung, and Blood Institute Scientific Statement. Circulation 112: 2735-2752, 2005.

21. The Examination Committee for Criteria of Metabolic Syndrome. Definition and criteria of metabolic syndrome. J Jpn Soc Intern Med 94: 794-809, 2005 (in Japanese).

22. Kadota A, Hozawa A, Okamura T, et al. Relationship between metabolic risk factor clustering and cardiovascular mortality stratified by high blood glucose and obesity: NIPPON DATA90, 19902000. Diabetes Care 30: 1533-1538, 2007.

23. Saito I, Iso H, Kokubo Y, Inoue M, Tsugane S. Metabolic syndrome and all-cause and cardiovascular disease mortality: Japan Public Health Center-based Prospective (JPHC) Study. Circ J 73: 878-884, 2009.

24. Kokubo Y, Okamura T, Yoshimasa Y, et al. Impact of metabolic syndrome components on the incidence of cardiovascular disease in a general urban Japanese population: the Suita study. Hypertens Res 31: 2027-2035, 2008.

25. Noda H, Iso H, Saito I, Konishi M, Inoue M, Tsugane S. The impact of the metabolic syndrome and its components on the incidence of ischemic heart disease and stroke: Japan public health center-based study. Hypertens Res 32: 289-298, 2009.

26. Kahn R, Buse J, Ferrannini E, Stern M. The metabolic syndrome: time for a critical appraisal: joint statement from the American Diabetes Association and the European Association for the Study of Diabetes. Diabetes Care 28: 2289-2304, 2005.

27. Grundy SM. Does the metabolic syndrome exist? Diabetes Care 29: 1689-1692, 2006.

28. Kahn R. The metabolic syndrome (emperor) wears no clothes. Diabetes Care 29: 1693-1696, 2006.

29. Reaven GM. The metabolic syndrome: is this diagnosis necessary? Am J Clin Nutr 83: 1237-1247, 2006.

30. Sattar N. Why metabolic syndrome criteria have not made prime time: a view from the clinic. Int J Obes 32 (S2): S30-S34, 2008.

31. Ruderman NB, Schneider SH, Berchtold P. The "metabolicallyobese," normal-weight individual. Am J Clin Nutr 34: 1617-1621, 1981.

32. Fox CS, Massaro JM, Hoffmann U, et al. Abdominal visceral and subcutaneous adipose tissue compartments. Association with metabolic risk factors in the Framingham Heart Study. Circulation 116: 39-48, 2007.

33. Pou KM, Massaro JM, Hoffmann U, et al. Visceral and subcutaneous adipose tissue volumes are cross-sectionally related to markers of inflammation and oxidative stress. The Framingham Heart Study. Circulation 116: 1234-1241, 2007.

34. Snell-Bergeon JK, Hokanson JE, Kinney GL, et al. Measurement of abdominal fat by CT compared to waist circumference and BMI in explaining the presence of coronary calcium. Int $\mathrm{J}$ Obes 28: 1594-1599, 2004.

35. Nakamura T, Tokunaga K, Shimomura I, et al. Contribution of visceral fat accumulation to the development of coronary artery disease in non-obese men. Atherosclerosis 107: 239-246, 1994.

36. Koutsari C, Jensen MD. Free fatty acid metabolism in human obesity. J Lipid Res 47: 1643-1650, 2006.

37. Oda E, Oohara K, Abe A, et al. The optimal cut-off point of Creactive protein as an optional component of metabolic syndrome in Japan. Circ J 70: 384-388, 2006.

38. Nagasawa N, Tamakoshi K, Yatsuya H, et al. Association of white blood cell count and clustered components of metabolic syndrome 
in Japanese men. Circ J 68: 892-897, 2004.

39. Ishizaka N, Ishizaka Y, Toda E, Nagai R, Yamakado M. Association between cigarette smoking, white blood cell count, and metabolic syndrome as defined by Japanese criteria. Intern Med 46: 1167-1170, 2007.

40. Saltevo J, Vanhala M, Kautiainent H, Kumpusalo E, Laakso M. Gender differences in C-reactive protein, interleukin-1 receptor antagonist and adiponectin levels in the metabolic syndrome: A population-based study. Diabet Med 25: 747-750, 2008.

41. Lakoski SG, Cushman M, Criqui M, et al. Gender and C-reactive protein: Data from the Multiethnic Study of Atherosclerosis (MESA) cohort. Am Heart J 152: 593-598, 2006.

42. Nakanishi N, Shiraishi T, Wada M. C-reactive protein concentration is more strongly related to metabolic syndrome in women than in men: the Minoh study. Circ J 69: 386-391, 2005.

43. Oda E, Kawai R, Sukumaran V, Watanabe K. LDL cholesterol is more strongly associated with metabolic syndrome in Japanese women than in men. Intern Med 48: 1607-1614, 2009.

44. Hunt KJ, Resendez RG, Williams K, Haffner SM, Stern MP. National Cholesterol Education Program versus World Health Organization metabolic syndrome in relation to all-cause and cardio- vascular mortality in the San Antonio Heart Study. Circulation 110: 1251-1257, 2004.

45. Oda E, Kawai R. Very low levels of high-sensitivity C-reactive protein are not bimodaly distributed but significantly related with other metabolic risk factors in Japanese. Intern Med 48: 953-958, 2009.

46. Ridker PM, Cook N. Clinical usefulness of very high and very low levels of C-reactive protein across the full range of Framingham risk scores. Circulation 109: 1955-1959, 2004.

47. Margolis KL, Manson JE, Greenland P, et al. Leukocyte count as a predictor of cardiovascular events and mortality in postmenopausal women: the Women's Health Initiative Observational Study. Arch Intern Med 165: 500-508, 2005.

48. Schwartz J, Weiss ST. Host and environmental factors influencing the peripheral blood leukocyte count. Am J Epidemiol 134: 14021409, 1991.

49. Facchini FS, Hollenbeck CB, Jeppesen J, Chen YD, Reaven GM. Insulin resistance and cigarette smoking. Lancet 339: 1128-1130, 1992.

50. Green MS, Jucka E, Luz Y. Blood pressure in smokers and nonsmokers. Am Heart J 111: 932-940, 1986.

(C) 2010 The Japanese Society of Internal Medicine http://www.naika.or.jp/imindex.html 